\title{
Raising Learning Awareness in the EST Classroom: Practical Application in a Lesson
}

\author{
$\mathrm{M}^{\mathrm{a}}$ Paz Kindelán \\ Universidad Politécnica de Madrid
}

\begin{abstract}
The promotion of learning strategies in the second language classroom has been one of the most widely discussed issues both in research and in application to teaching practice. The incorporation of strategy training in the course syllabus of the language class requires a combination of instruction of the subject contents and the development of learning strategy awareness through tasks and activities completed by students. Particularly, when learning English within a scientific or technical course, this awareness-raising process has to be integrated in the teaching materials that are largely related to the specific ends for which the language is taught.

This paper presents a unit of a required English course taught in a mining engineering degree, in which students are exposed to a number of strategies that they may become aware of with appropriate direction. Although the majority use learning strategies, as demonstrated in previous research within the same context, the lecturer should make them reflect upon the techniques or tactics employed in the process of learning a second language, thus helping them become more efficient and autonomous language learners..
\end{abstract}

\section{Introduction: some evidence of learning strategy use in a formal classroom setting.}

In an article on the crucial aspects of learning strategy definition and classification, Oxford $\&$ Cohen discuss some of the current problems in second language learning research, for example: the difference between strategy and tactic; whether strategy acquisition is a 
conscious or unconscious process; criteria applied to differentiate strategies; the concept of strategic competence, ${ }^{1}$ etc. They also propose diverse solutions to those issues and, above all, encourage greater and deeper study-based on consensus-of what really constitutes a learning strategy and its taxonomy.

Until now, the various procedures used to obtain more detailed information on strategy usage (questionnaire, interview, protocols, student diaries...), especially in the classroom setting $^{2}$, have provided the following conclusions (Oxford \& Crookall 413-4):

- The learner actively involves himself in the language learning process.

- All learners, regardless of their level, use strategies.

- Some, if not all, are mostly unaware of the strategies they employ and do not take full advantage of them.

- Apparently, those more capable learners utilize a larger range of strategies in many situations, although the relationship between the level of competence in the language and the use of learning strategies is a complex issue.

- Upper level and lower level students tend to employ different strategies.

- There is growing evidence of the influence of certain factors such as race, culture, aptitude, sex, learning style and so on in the choice of learning strategies.

- It is possible and advisable to teach strategies by means of well informed training, making learners conscious of how and why they use them. At the same time, they should learn to transfer strategies to different contexts and evaluate them.

- Learning strategy training is more effective when it is integrated in the normal classroom activities as well as when the nature and difficulty of the learning task are taken into account.

In our previous research study (Strategies used by Mining Engineering Students 111-5) on the use of learning strategies in an EST environment, we demonstrated that mining engineering students of the Technical University of Madrid use a wide range of learning strategies, precisely those attributed to the good second language learner. Most students employ them mechanically and habitually (after years of language learning) rather than with conscious effort.

It was also concluded that in comparison with the advanced group, beginner and intermediate level learners utilise a greater number of metacognitive (mostly planning and self-evaluation) and cognitive strategies (inferencing and resourcing). The advanced learners resort to more sophisticated strategies which involve reorganization and transformation of material such as "recombination", less frequently employed by the lower levels. In effect, "recombination" requires a highly cognitive process: the organizing of acquired learning in order to produce more elaborate sequences in the second language. It is reasonable to expect that less proficient students are only capable of grasping the relevant points or the general idea of the discourse. Probably, once they have internalised the information, they will reproduce it verbally or in writing. On the other hatid, more proficient students will, in addition, combine previously acquired knowledge of the second language to construct new 
and more complex meaningful sequences. At this point, language competence and strategic competence converge.

Nonetheless, all three groups actively involve themselves in the learning process and show abundant and varied use of metacognitive, cognitive, social and affective strategies in the formal classroom setting where the study was conducted. The influence of other variables affecting choice of language learning strategies (motivation and attitude, study habits...) was not evaluated, even though it was taken into account in the correlation analysis of the data obtained after applying the research tools (125-9).

Given the results of the abovementioned research, a second phase of the study has been contemplated with the aim of training mining engineering students in a series of specific strategies that enhance communicative competence. In this way they are faced with the challenge of achieving a greater degree of self direction in their learning. This strategy training component, originally planned to be included in the empirical investigation previously mentioned, would encompass natural classroom instruction combined with the syllabus of the official teaching programme.

With this purpose in mind, we have designed a teaching unit which serves as a model to follow in the elaboration of a lesson plan applied to a concrete area within the degree-in this case, geology. It brings into play a communicative use of the language with the fostering of several strategies that students are presented with as part of the learning process. But first the introduction of a strategic training component means bringing teachers' attention to the possibilities of using learning strategies as a basic element of their instruction. This latter development implies raising their awareness and understanding of the process in order to provide students with the appropriate practice, encouragement and the actual training that optimizes such learning:

By using teaching and instructional methods that cue, demonstrate, and reinforce the use of learning strategies, instructors can enhance their students' ability to be independent and effective learners while also teaching the content-specific material in a course (Weinstein \& Underwood "Learning Strategies: The How of Learning" 255).

Implementation of such a programme would necessitate not only a heightened self-awareness among lecturers of how students are learning and why, but would also provide the learner with opportunities for engaging in active learning and interaction. Verbal reporting systems aimed at identifying learning strategies can be incorporated into classroom activities by having students verbalize their thoughts as they actually perform the tasks. This, above all, contributes to develop "metacognitive strategies" (planning, monitoring and evaluating) as they describe their own thinking processes and discover those of their classmates.

As teachers, we have innumerable occasions to make students conscious of those "tactics, operations and tricks" that enhance their learning potential. As explained by Weinstein Underwood, the teacher that makes an analogy between the topic being dealt with and an everyday event is attempting to help the students to use their previously acquired knowledge to elaborate a new concept with the new information, making the latter more meaningful. 
Thus, when s/he uses graphic examples pertaining to the real world to illustrate a particular principle, s/he is aiming to relate to the learners' individual experience. Converting these teaching strategies into learning strategies is just a matter of making these techniques explicit for the student. Instead of presenting an analogy and continuing with the lesson, the teacher may take a few minutes to direct students' attention to the strategy employed, explain why such strategy may help them learn the new information more easily, and how they can incorporate it into their study habits. This procedure may be insufficient in order for the majority of students to resort to "analogy", for example, as an information processing strategy. However, repeated exposure to this and similar techniques in diverse contexts, over a period of time, in conjunction with the appropriate stimulation to use strategies and the subsequent feedback on the part of the teacher can contribute to the development of effective learning strategies in the student (255).

Our approach will then focus on paying more attention to process through specific materials related to the special purpose for which the language is being learnt, instead of measuring students' performance in terms of the final product in the L2. So, beyond straightforward completion of learning tasks, we will draw learners' attention explicitly to how the activity is being accomplished, thus highlighting its inherent processing character: for example, asking how did you go about doing this?' which way of doing this works the best for you?' what tactics have you used in solving the problem?'

Certainly, there will be many strategies that the learners will be using and they will not consciously register, but the aim is not so much confronting them with a myriad of techniques as making them develop more self-awareness of their procedures and also improve their latent strategies. Thus, a communicative task-as stated by Willing-prompts the joint operation of certain learning and communication strategies which work simultaneously to solve the problem, taking into account the linguistic resources necessary for doing so: "In the same act, the learner thus learns how to learn and learns language" "Learning Strategies as Information Management" 150).

Therefore, it is ultimately the teacher's pedagogical decision whether to raise awareness on learner's strategies and give practice in particular instances, or leave the issue aside. Hence, it could be suggested that instructional methods and practices as well as course objectives and the nature of classroom tasks all influence the learner's selection and use of strategies. For example, the teaching of communicative notions and functions through systematic explanations with examples will result in the development of cognitive strategies such as reasoning and information analysis within a structured syllabus, typical of traditional approaches. On the contrary, the implementation of these functions, by means of activities demanding the use of the language in a real situation, leads to the application of other strategies: compensation strategies, such as focusing on contextual clues to guess the meaning of unknown words or terms; social strategies, for instance, asking the speaker when clarification or verification of a concept is needed, or seeking the cooperation of peers for the same purpose; even metacognitive strategies like self-monitoring in the oral production of the L2 within a conversation, discussion or debate. These strategies are intended to provoke a spontaneous and authentic exchange in the target language in keeping with a 
communicative approach. Our purpose is to bring them into the students' conscious mind in order to promote self-direction in their learning.

\section{Task designed for learner strategy training: example of a lesson plan.}

\subsection{Course features}

Within the Spanish University's new curriculum, recently revised according to E.E.C. directives, the study of English as a foreign language is contemplated as an elective for Science and Technical degrees. Nevertheless, some Faculties and Schools require undergraduates to take an English course applied to their major, as in our case "Scientific and Technical English". This course is taught in the third year of the mining engineering studies and has six credits ( 60 contact hours). Its syllabus covers a range of specific topics in English dealing with the different areas of the degree: energy, metallurgy, geology, mining and general engineering. It consists of twelve units with the following objectives:

- In-depth study of the main structures of English grammar. Students must have a basic knowledge of the language, usually acquired at school.

- Assimilation of technical vocabulary peculiar to the abovementioned areas.

- Analysis of scientific and technical texts mastering the appropriate skimming and scanning reading skills, distinguishing relevant from non-relevant information, designing graphs and diagrams, and using connectives.

- Composition of texts in English adopting a logical and suitable structure and complying with the distinct conventions of each genre: abstract, report, research paper...

- Reinforcement of listening and speaking skills by way of communicative practice in the classroom and the completion of exercises/activities in the language laboratory.

Given these objectives, next, we will describe a unit in which the lecturer, through explicit presentation and demonstration of the strategies involved in completing the tasks, will lead learners to explore their own use of techniques for language learning within their capability. This lesson is about "Minerals and Rocks" and it is divided into two sections.

In terms of the subject matter, the texts of this unit refer to one of the mining engineer specialities, geology, with the subsequent interest for students.

With regard to the functional aspect, this lesson emphasizes several functions characteristic of scientific discourse rhetoric: 1) visual-verbal relationship, that is, comprehension and interpretation of charts, tables, diagrams, graphs and all sorts of schematic illustrations; 2) classification, very useful in order to organize information drawn from a text, or to differentiate its key ideas; 3 ) explanatory description, which usually requires a diagram showing the organization of the data to make it clearer.

From a linguistic contents point of view, the grammatical structures as well as the lexis commonly used to express said functions are studied. Other points relevant to scientific language are also reviewed: certain Greek-Latin affixes, formation and use of "preposed 
modifying clusters" as well as some standard abbreviations and symbols. Finally, vocabulary previously introduced in the elective courses (Technical English I and II) is expanded with the help of the texts, within the semantic field of geology.

The course aims defined for this unit should lead students to:

- Learn to interpret the visually introduced information and be able to transfer it to the oral and written media.

- Identify the manner in which information is organized or classified in the scientific discourse, according to concrete criteria.

- Predict the text contents with the aid of extralinguistic information or to infer the meaning of words and expressions using contextual clues.

- Establish relationships between the information provided on a topic and their own knowledge of it or expand it with additional sources.

- Become personally and actively involved in tasks or activities which demand communicative practice in the L2, expressing their opinions and learning to negotiate, within a group, the solution to the problems posed.

- Achieve certain ability in working with a monolingual dictionary to increase vocabulary in the foreign language.

Lastly, the proposed tasks and their grading clearly illustrate our main objective in the designing of the materials of our course syllabus: integration of the four skills.

\subsection{Teaching unit: Minerals and Rocks}

I. First section: Minerals

1. Presentation: the lecturer begins by introducing the subject of minerals and their identification.'

*Brainstorming and elicitation:

a) What are minerals? Definition.

b) What tests are used to identify minerals?

- Check with a transparency of background information on the overhead projector and explain each test to the class (see Appendix).

- Advise students to take notes on the presentation so that they may use information for subsequent tasks.

- Make students look at a new transparency with pictures of the four tests already seen and ask them to answer the questions orally. 


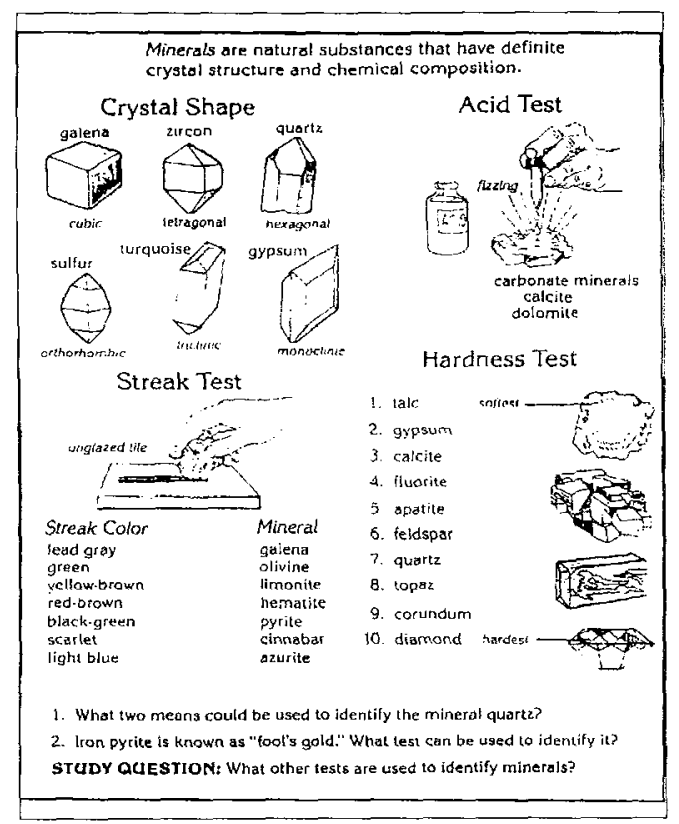

Figure 1.

2. Paragraph writing: Bearing in mind the information already presented, make complete sentences out of the following notes, by putting the verbs in brackets into the right tense. Then, arrange the sentences into a paragraph. Make sure the sentences follow each other logically and that the paragraph makes sense.

1.

the/earth's crust/minerals/make up/which/the/rocks.

(make up of)

2.

earth's surface/substances/minerals/naturally/on/occurring/the.

(be)

3.

structure/definite/crystal/they/composition/chemical/and.

(have)

4.

minerals/accurately/can/be/identification/the/of/in/analysis/laboratory/by/the/chemical. (determine) 
5.

however/often/geologists/for/necessary/it/identifications/make/field/to/the/in.

(be)

6.

observing/physical/they/this/characteristics/by/the/and/chemical/performing/by/simple/ and/tests/physical.

(do)

3. Listening for detail: understand a lecture on various types of minerals. ${ }^{3}$

*The lecture is divided into six sections, one on each mineral. Using the information the lecturer gives you, complete as much of the table below as you can.

Table 1.

\begin{tabular}{|c|c|c|c|c|}
\hline$\overline{\text { Mineral }}$ & Formula & Colour & Hardness & Uses \\
\hline
\end{tabular}

II. Second section: Rocks

4. Intensive reading: understand a printed text on classification and formation. ${ }^{4}$

4.1. Check your understanding: oral comprehension questions.

- Look at the first part of the text about rock classification. The writer states a basic problem. What is it?

- Then he considers some possible answers to the problem: What are they?

Why does he reject these possible answers?

- What criterion does he finally choose for the classification of rocks?

- Explain in your own words the difference between igneous, sedimentary and metamorphic rocks.

4.2. Put in the correct order some jumbled sentences according to the information in the text:

1. We might disregard composition and classify rocks according to their origin.

2. At first glance, it is not obvious how rocks can be separated into definite categories.

3. A fundamental division of rocks into three main groups according to origin is agreed on by nearly all geologists: igneous, sedimentary and metamorphic rocks. 
4. Yet rocks of widely different structures and origins may have nearly the same mineral composition.

5. A further classification based on chemical compositions has the difficulty that these are not evident in the field but require laboratory analysis.

6. An initial classification of igneous rocks is provided by mineral composition.

4.3. Look at the three separate illustrations of rock formation and complete the worksheets, ${ }^{5}$

- The three transparencies on formation of igneous, sedimentary and metamorphic rocks are shown consecutively on the overhead projector with the corresponding explanation. - After each transparency is removed, students complete the corresponding worksheets.

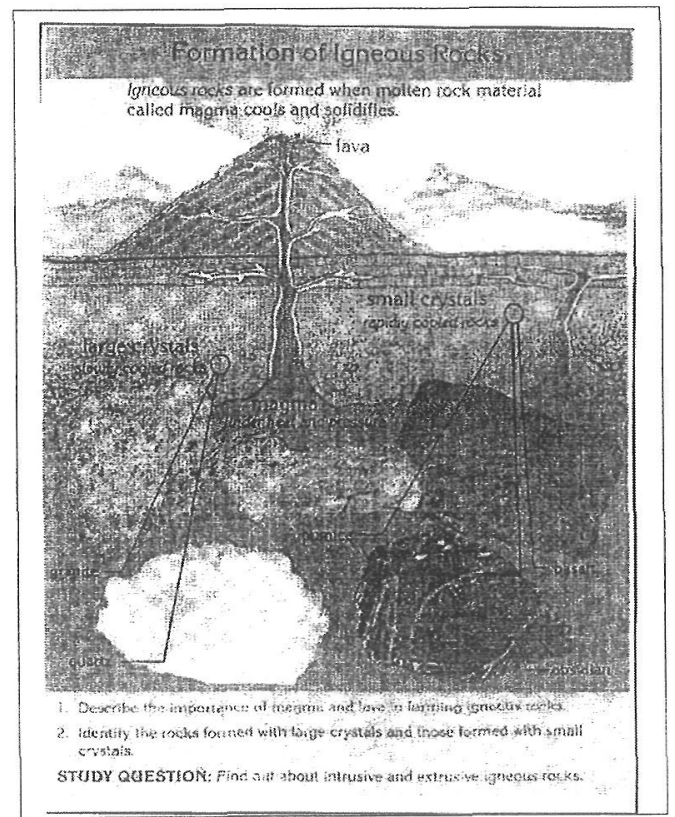

Figure 2.

4.4. Now, fill in the table with all the information you have gathered from the diagrams and sheets. Use additional knowledge if known or any other sources at hand. 


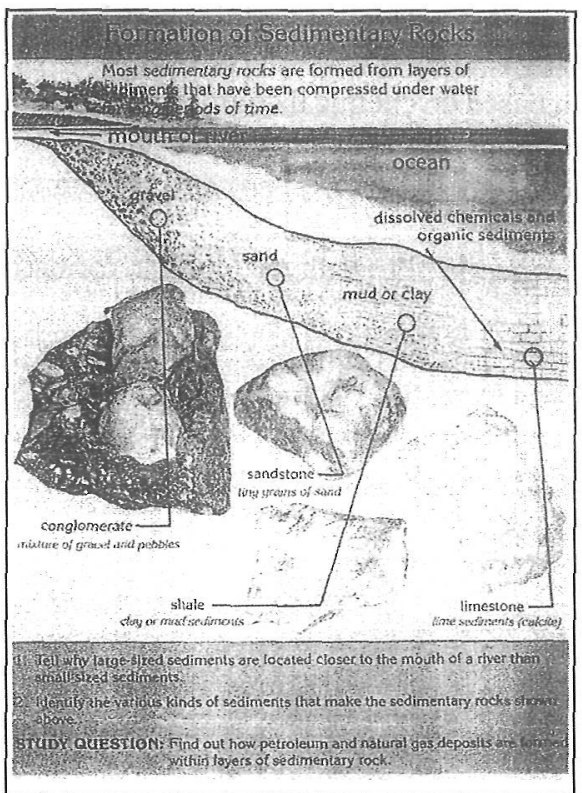

Figure 3.

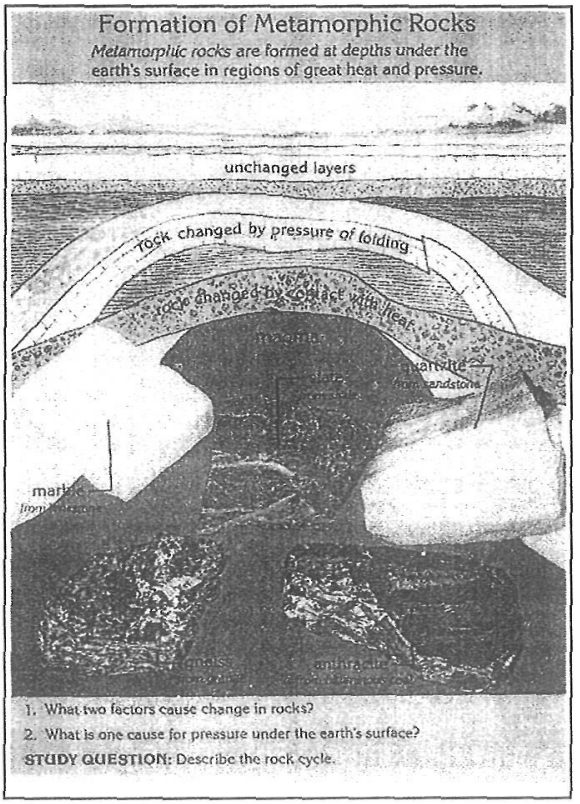

Eigure 4. 


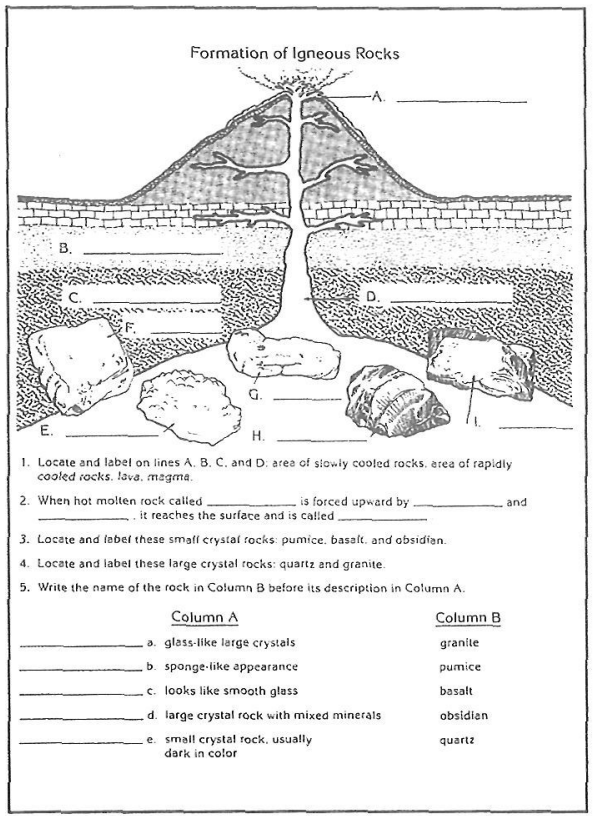

Eigure 5.

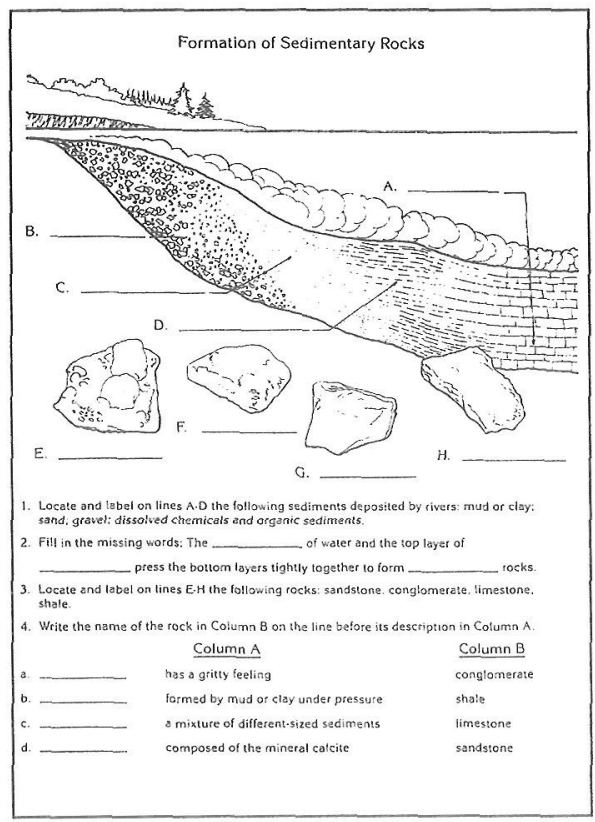

Eigure 6. 
Table 2.

\begin{tabular}{|l|c|c|c|}
\cline { 2 - 4 } \multicolumn{1}{c|}{} & $\begin{array}{c}\text { IGNEOUS } \\
\text { ROCKS }\end{array}$ & $\begin{array}{c}\text { SEDIMENTARY } \\
\text { ROCKS }\end{array}$ & $\begin{array}{c}\text { METAMORPHIC } \\
\text { ROCKS }\end{array}$ \\
\hline FORMATION & & & \\
\hline CLASSIFICATION & & & \\
\hline CHARACTERISTICS & & & \\
\hline
\end{tabular}

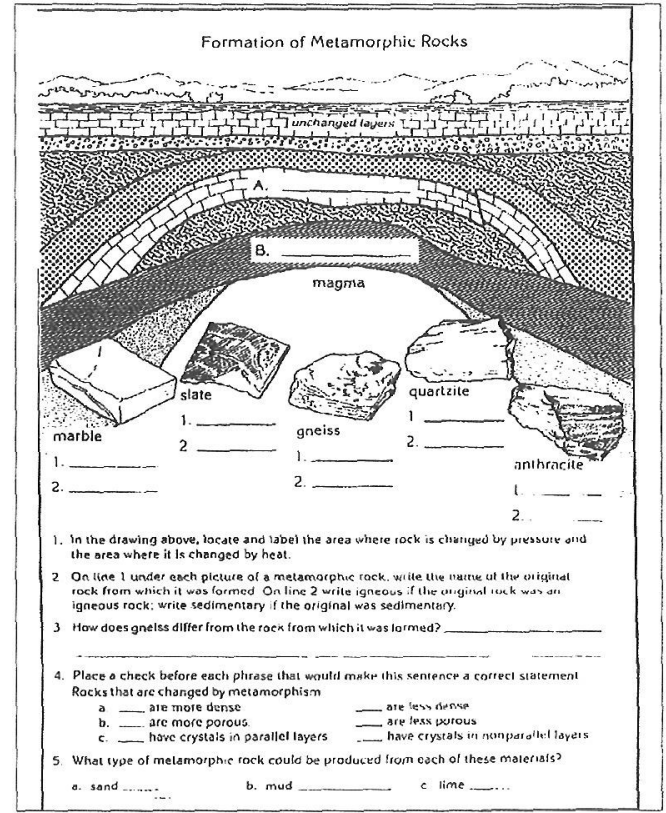

Figure 7.

\section{Vocabulary work:}

5.1. Make a list of the 'preposed modifying clusters' that appear in the text and then write full length sentences from them, without changing the meaning:

Follow the model:

*coarse-grained rock: a rock which has coarse grains. 
Here are some of them:

*well-formed crystals:

*six-sided prisms:

*blunt-pointed ends:

*light-coloured material:

*rock-forming minerals:

5.2. Word formation: the following words are in the text. Use your dictionary to find the other parts of speech:

Table 3.

\begin{tabular}{|c|c|c|}
\hline Adjective & Noun & Verb \\
\hline crustal & & \\
intrusive & & \\
light & hardness & \\
& variety & describe \\
\hline
\end{tabular}

5.3. Prefixes and Suffixes: Underline all the words you can find in the text with the following prefixes and suffixes:

Suffixes:

$-\mathrm{y}$

-ive:

-al:

-ly:

Prefixes:

over-:

re-:

im-:

un-:

5.4. Match the abbreviations corresponding meanings: 
Table 4.

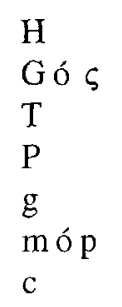

\begin{tabular}{l|l} 
stands for & $\begin{array}{l}\text { pressure } \\
\text { mirror symmetry plane } \\
\text { density } \\
\text { temperature } \\
\text { center of inversion } \\
\text { hardness } \\
\text { glide plane }\end{array}$
\end{tabular}

Read out these formulas:

$\mathrm{CaCO}_{3}$ :

$\mathrm{CaSO}_{4} 2 \mathrm{H}_{2} \mathrm{O}$ :

$\mathrm{SiO}_{2}$ :

$\mathrm{Al}_{2} \mathrm{O}_{3}$ :

$\mathrm{C}$ :

$\mathrm{CaF}_{2}$ :

$\mathrm{PbS}$ :

\section{Some of the strategies exercised in the completion of learning tasks.}

The tasks proposed throughout the unit give students the chance of using a large array of learning strategies. Probably, they will activate their learning potential to acquire, store and retrieve information in the second language by means of several techniques: for example, looking for similarities between new words and L1 words, planning what to say ahead of time, searching for overall meaning in reading, guessing meaning from context, etc. It is impossible to enumerate all the learning strategies that the learner brings into play to solve a particular task or activity. In addition, it has been widely researched that the selection of strategies varies according to several factors as shown in a review by Oxford ("Use of Language Learning Strategies" 1-13). However, what we, as educators, can do is provide learners with guided direction to:

-Recognize their current strategies

-Show them more effective strategies related to specific language tasks.

-Demonstrate how a learning strategy helps them to better comprehend and retain the L2. -Allow them to practise the new strategy with other tasks.

This instruction should be conducted as part of classroom interaction, where teacher and students work together to develop consciousness and understanding of students' use of techniques. It is not intended that the following strategies be the only ones fostered in the course of activities; many others will become evident. Within the scope of this paper, we have merely highlighted a few according to Rebecca Oxford's classification (Language Learning Strategies 17-21):

\subsection{Direct Strategies}




\subsubsection{Memory Strategies}

A) Creating mental linkages and applying images and sounds

Transferring information from a diagram to a written text and viceversa stimulates the application of mental images that associate the new linguistic information with concepts already existing in one's memory. Students will group, classify and label what is heard or read into sets or categories that make the material easier to remember. Whether links be simple or complex, common or strange, they should always be meaningful for the learner. Particularly, for vocabulary building, students can use various criteria for associating words: grammatically, conceptually, semantic mapping, etc. For instance, in task 5.4 they have to scan a printed text and identify examples of words containing concrete prefixes and suffixes. In addition, there may be a visual or aural link: the former when the materials included in an exercise or activity generate an image that refers to something familiar (e.g. use of keywords that give rise to a mental picture of the new word in English interacting with a familiar one: "prism" is associated with a prison and the learner pictures a jail in his mind), and the latter when sounds are retained in memory that will help recall known or save newly acquired information (e.g. similarities between the root of a new word and that of a known word in English or correlation between the spelling of some words in L1 and L2: gneiss, mica... See key to task 3 in Appendix). In the diagrams shown in this unit, the learner can make links with his/her own knowledge of the subjects akin to the curriculum (geology, mineralogy).

Then, when reviewing the new material already learnt in the target language, s/he will practise sets of vocabulary words at different times and in a meaningful way, for example, putting them in contexts or recombining them to make new sentences.

\subsubsection{Cognitive strategies}

\section{A) Practicing}

Repetition is one of the most innate strategies for a language learner. Listening to a passage several times, rehearsing the same dialogue or phrase, imitating a native speaker, reproducing his/her pronunciation and intonation, etc. are some of the characteristic practices of this strategy throughout the learning process. The learners of Scientific and Technical English usually encounter difficulty when identifying the names of minerals or other specific terms because they are accustomed to their "spanglish" pronunciation (e.g. mica/mika/ instead of /maik, Upon listening to a recording in the L2, they realise their mistake and try to adjust their diction, focusing on the original and repeating the words over and over again.

Recombination: In order to compose a paragraph or describe the different types of rocks, the student will take familiar elements of the language and combine them in such a way as to create a new, complete and fully meaningful sequence. For example, in the building of a coherent and cohesive paragraph starting from some jumbled notes (see task 2), s/he will have to rely on the information previously gathered from the text, on his/her knowledge of 
linguistic for.as and discourse structure, and finally on the specific vocabulary learnt up to this point.

\section{B) Receiving and sending messages}

Getting the idea quickly: this strategy is employed right from the start of the course for listening and reading tasks. Students have to focus on general points or specific details of the passage in order to fill out diagrams and complete charts or simply answor some comprehension questions. So skimming and scanning the texts searching for information are two main skills practised continuously during the course. This unit entails several activities in which this strategy becomes clearly useful: "note-taking" in the presentation of the lesson; "listening for detail" in task 3; and "intensive reading with oral comprehension questions" in task 4.1 .

Resourcing: When working with vocabulary belonging to this field (geology), it seems logical for students to resort to a dictionary, preferably monolingual, as reference material to check the definition of the words they are unfamiliar with. They will also have to use it for vocabulary building (task 5.3 ). Some other additional sources such as their notes from a parallel course on mineralogy or a textbook will be of great help in expanding on the topic of rock formation and classification needed to complete table 2 (task 4.4).

\section{C) Analyzing and reasoning}

Students need to exercise reasoning and analysis to determine the linguistic elements which make up the L2 sequences and the rules that should be applied when ordering, classifying, grouping information and listing the items, all of which should be consistent with certain criteria. When listening for detail (task 3), they will derive hypotheses about the meaning of what is heard through their knowledge of the language code (deduction). In addition, they will analyze contrastively, that is to say, compare sounds, vocabulary and grammar of their mother tongue with those of the $\mathrm{L} 2$ so as to establish similarities and differences between them. And finally, they will analyze complicated expressions such as "coarse-grained rocks" or similar by breaking down phrases into their components (task 5.2: how preposed modifying clusters are arranged into meaningful language sequences).

In the same way, transferring, directly applying the knowledge of words, concepts or structures from one language to another, with the same purpose as translating, is quite a useful strategy, particularly for the beginner. Translation will also help him/her understand new phrases in the $\mathrm{L} 2 \mathrm{using}$ the $\mathrm{L} 1$ as a point of reference.

\section{D) Creating structure for input and output}

In the first section of the unit, where the lecturer introduces the subject of minerals and asks students a series of questions on the content, two fundamental strategies convene: note-taking and hichlighting relevant information by underlining or colouring, for example. In effect, the students will endeavour to take notes of the essential information and highlight the most 
important aspects or principal ideas that then will be used not only to respond to the questions posed, but also to re-structure the paragraph in the following task.

On the other hand, summarizing what they have heard or read improves understanding and organizing the language input and information received. This could be introduced in any stage of the unit to check learning progress.

\subsubsection{Compensation strategies}

\section{A) Guessing intelligently}

The students will compensate their lack of understanding of and/or their inability to express themselves in the second language by paying special attention to linguistic clues (e.g. affixes, word order...) and visual aids (text structure, pictures...). To give an example, they can guess the meaning of the words "readjustment" or "alignment" of the mineral particles by focusing on the prefix re-and suffix -ment. They can also assimilate the data of a text based on the immediate context and their own knowledge of the topic: in listening, the speaker's organizational use of words, letters or phrases that show importance can be noted (e.g. first, next, finally, let us turn to...), and guesses can be made from prior information about minerals and their properties.

\section{B) Overcoming limitations in speaking and writing}

When carrying out the activities comprehended in this unit, students, on more than one occasion, will resort to the mother tongue, that is, translating from $\mathrm{L} 2$ to $\mathrm{L} 1$ and viceversa whenever they encounter difficulty in expressing themselves. In the same manner, they will try to make themselves understood by describing the concept (circumlocution) or searching for a synonym to convey the information. Another possibility is adjusting the message by omitting certain elements of the topic being transmitted or simplifying the ideas. Lastly, they may seek the help of the teacher or peers who will provide the term or the proper expression in the L2. In task 4.1 (comprehension questions), students try to express themselves in English when they are asked the questions, resorting to any of these tactics to master their limitations in speaking.

\subsection{Indirect Strategies}

\subsubsection{Metacognitive strategies}

\section{A) Centering your learning}

Students should pay special attention to the data collected in the diagrams and schematic illustrations in order to work with them (arrange, classify, contrast...) in ensuing written activities, or on the contrary, to transfer the information obtained from a listening passage to a table or graph. Task 4.3 is a clear example of this way of proceeding: they have to locate and 
label various items on the diagrams of the worksheets which may activate some useful strategies that the good learner has at hand: to decide in advance to attend to specific aspects of the language input (selective attention) or to attend in general to the specific task and ignoring irrelevant distractors (directed attention). Both of them contribute to center their attention on the learning task after being previously introduced to the data through the transparencies.

\section{B) Arranging and planning your learning}

One strategy stands out in this group: identifying the purpose of a task or activity whether it be written, aural or oral. If students are clearly aware of the aims that should be met in doing the exercises, they will be able to organize and better plan the learning of the new linguistic material more easily.

On the other hand, planning and rehearsing in advance those linguistic components and functions needed to complete a task or activity can also help students successfully "dive" into its contents. One example could be the construction of a paragraph in task 2, in which they will anticipate certain principles and test various possibilities until they build up not only the grammatical structure of the sentences but also produce a coherent and cohesive final text.

\section{C) Evaluating your learning}

The good language learner controls, evaluates and directs his/her own learning constantly. For this reason, the motivated and diligent student will bring into play self-monitoring and selfevaluation strategies from the beginning of his/her exposure to the L2:

- S/he acknowledges and supervises his/her understanding of and production in the second language striving for accuracy in pronunciation, grammar and vocabulary.

- S/he checks and assesses the results of his/her performance in the L2 against an internal measure of completeness and correctness.

This double process is achieved, in this case, as a consequence of the feedback received in classroom interaction between teacher-student and student-student upon reviewing exercises and tasks. Several opportunities will be provided by the teacher to verify how well students had made themselves understood and to discuss their communicative effectiveness.

\subsubsection{Affective strategies}

In this field, each individual measures his/her own affective response to the learning process. However, it would be convenient for the teacher to be sensitive to the atmosphere created in the class so as to offer students a chance to:

A) Lessen their fear or anxiety when participating in tasks using the L2 by allowing the student to fall back on the mother tongue occasionally to solve a problem of oral 
communication. S/he can also sporadically introduce a warmup exercise before tackling a specific activity. All this will dissipate tension and gradually bring about a positive and congenial climate in the classroom.

B) Help themselves overcome their reticence by inviting them to use the L2 without fear of ridicule or of committing unforgivable errors, and by recognizing their efforts.

\subsubsection{Social strategies}

It is quite obvious that these strategies are very common in our context since we attempt to establish a sense of teamwork and mutual help among students. Despite the fact that the learner will reach beyond the classroom walls looking for empathy and fostering an open-minded approach to the foreign culture associated with the language, s/he will pursue the cooperation of the teacher and peers in order to:

A) - Clarify a linguistic question or problem

- Verify his/her progress in the L2

- Correct his/her errors in the second language

B) -Ask for help to carry out a particular task or exchange information and pool the results.

The arrangement of the classroom in pairs or small groups is the most efficient system for working out solutions to tasks, allowing students to use the L 2 in a communicative way, and at the same time diminishing their anxiety in language performance.

To sum up, all these foregone procedures will be accompanied by opportunities for the learners to reflect on these strategies, and to examine their effectiveness and applicability. As mentioned at the beginning of this paper, it is only a question of taking a little while to direct students' attention to the strategy employed, make them realise why such strategy is helpful, and give them a chance to use it on various contexts. In this way, they are encouraged to gain self-awareness of the way they themselves learn.

\section{Suggested procedure for strategy training}

It would be very complex and lengthy to explain how each of the abovementioned strategies are brought into the students' conscious mind in the tasks proposed. However, we advance a procedure that may be applied with a different perspective in each category of strategies. The sequence in which strategies are taught depends upon the order of learning tasks. Also, in addition to the strategies employed by students to carry out the task (possibly in a subconscious way), others are suggested, discussed openly and tested for effectiveness.

To introduce the strategic component in the classroom, a series of procedures have been defined according to different experts in the field ("An action plan for strategies" in Wenden Learner Strategies 97-117). We have chosen to apply the following stops. Firstly: 
1) The teacher defines the strategy in which s/he wishes to train his/her students.

2) S/he decides which communicative skill or linguistic aspect is most relevant to the strategy and which tasks are most appropriate to this aim.

3) S/he considers and selects the materials necessary for strategy training, which can be found in the class textbook, or must be developed and adapted from other sources.

Secondly, one needs to bear in mind these questions: - What is the purpose of this task? - What type of $\mathrm{L} 2$ processing and production is involved?

- Should the strategy be made explicit at the beginning of the task or at the end? or perhaps sometime during the lesson?

- Is this the only way this task can be completed? If not, could other students perform the same task and then compare the strategies used?

- Are there any other strategies that might complement the one in question, making it easier to use?

However, before contemplating any procedure, we recommend devoting the first week of class to sensitize students to the concept of autonomous learning. This implies discussing with them factors that come into play in second language learning as well as discerning what type of learners they are, how they approach the learning task, how they assess their performance in the language (via a questionnaire on learning styles: 'what sort of language learner are you?' in Ellis \& Sinclair 6-9). Finally, students must discover what resources they have to overcome obstacles or simply improve their competence in the L2.

This week of orientation, called pre-course counselling by Ellis \& Sinclair, should predispose students to see learner training as an ongoing process fully integrated in the course, and should also minimise any resistance or mismatch of expectations with regard to the learning objectives.

Returning to the procedure itself and in order to make it explicit to students, we could take cognitive strategies and focus, for example on listening and note-taking (see 3.1.2.B: Getting the idea quickly) in order to answer questions or complete a chart at the beginning of the lesson. The steps involved in the process of raising students' awareness about the use of this strategy may be the ones developed by Wenden (Learner Strategies 63):

1) Students are given the title of the lecture:

a) They tell what they already know about the topic (eliciting background knowledge).

b) They make predictions on what the lecture will about (prediction).

They are told these are two pre-listening strategies and asked to discuss why they are important.

2) Technical vocabulary and key words that students may not know are presented.

3) An introspective procedure follows: a) Students are told to stop after one idea/sentence during the lecture; b) at the pause, they should write down what they are thinking (not taking notes).

4) The procedure is illustrated by having students respond orally for the first few pauses until they become familiar with it. 
5) Then they write their responses by numbering them sequentially. Each number should correspond to the idea in the lecture used to elicit their thought processes (e.g. 'I'm thinking how to listen to the lecture.'..; 'what I have to do with the language'; 'That's one of the ways I learned English').

6) Some students responses are written on the blackboard together with the ideas that elicited them.

7) Students are told that these responses, the 'thoughts' that come to their minds as they listen, are called strategies and that the aim of the lesson is to learn to use note-taking, a strategy that can help them understand academic lectures.

8) Finally they compare the different responses to determine the different strategies that they have employed (e.g. selfquestioning, association).

9) The introspective reports are collected and used by the teacher as a source of information on the listening strategies used by students.

10) The lecture is now given from beginning to end with students taking notes.

Let's now move on to metacognitive strategies, e.g. identifying the purpose of a task or activity (within the category of arranging and planning your learning, see 3.2.1.B). In a writing task (4.4), where they have to fill in a table with information already presented and using additional knowledge on 'rocks', students may practise self-monitoring their production in this way:

1) Students are explained that writing is an on-going process which requires supervision and evaluation.

2) They are asked to write down what they think is the aim of the task.

3) Compare the stated aim with that of partners and also the teacher's intended purpose.

4) Students go through their notes and worksheets on the formation \& classification of rocks and find problems/areas they are unclear about. Then they ask questions for clarification and these are registered on the blackboard.

5) Students complete the table with the information in each box, but from time to time they are interrupted and asked to look at what they have written and compare it to a given list of evaluative statements.

6) After having identified the statement that best reflects their impression of their written work, they are again asked to think about what they can do to solve the problem, if there is one. For this purpose, they are provided with a list of remedial tactics from which they can take ideas about what to do.

7) This is done throughout the writing process. It might be useful to ask students to stop after every other sentence or box they fill in, so that the whole class is not interrupted.

8) When the task is completed, students are asked to think about the use of the activity, check its main aim once again, and assess what they have learnt.

9) The teacher prepares a set of substitution strategies that may help students improve their writing after having identified their problems and decided to adopt some tactics. 
Lastly, in learning vocabulary, there are memory strategies (see 3.1.1.A) that students can be made aware of in various ways. One common procedure is to encourage them to experiment with their own strategies and let them acquire others from their peers as follows:

1) The teacher writes a list of unknown vocabulary with its definition and/or translation on the blackboard and tells students they have to learn it since they will be tested later on.

2) Students are given 5-10 minutes to learn the vocabulary items. In the meantime, the teacher observes the learners' behaviour. This is important so that s/he can later ask more focused questions.

3) The teacher erases vocabulary from the blackboard, and tests students.

4) Before checking the answers, the teacher asks the students to make a note of how they learnt the words (suggests things like "writing them down several times", "repeating them to oneself", "grouping them according to their sound/meaning/form/grammatical category". See Creating mental linkages and applying images and sounds", 3.1.1.A).

5) Answers to the test are checked. Students are then asked to tell each other how they learnt the words. A list of possible techniques is written up on the blackboard. Here the teacher can use the information gained from the observation of students' behaviour.

6) Teacher and students discuss the activity, and whether it was useful. At this point, the teacher can reveal and name the strategies that have been utilized in the process and present new ones. It is also important to emphasize that different techniques work for different people.

7) As a follow-up activity, a new list of vocabulary is given and students are invited to experiment with various strategies for learning the words. Then they assess how well this new method worked for them.

These guidelines have been developed to promote awareness on the students' part and make strategies explicit. They include verbal reporting from students about their mental processes, feedback on the part of the teacher, and discussion with students about the learning process, and they demonstrate how strategy training may be implemented into the normal teaching without implying any major changes to the normal classroom procedures. Raising students's awareness about language learning and the role they have to play in it can be favoured by very simple tactics, namely, having them assess their own performance, posing a series of instrospective or retrospective questions when completing tasks, and explaining the purpose of doing certain exercises with them, etc.

In order to evaluate the strategic component throughout the course, a number of instruments should be applied to gain information on the effectiveness of the methods or techniques employed in the training. In this way, teachers and students could adjust the existing learning plan, introducing modifications as necessary.

The information can be obtained by means of:

1) An 'informal conversation' with students: after each lesson they are asked which tasks have been most helpful and why.

2) A 'questionnaire' in which students give their opinions, achievements and expectations of the classwork (e.g. meaning of the activities carried out and whether the strategies used improve their skills in the L2, and their degree of motivation). 
3) Finally, students' 'diaries' have proved to be a successful instrument in the classroom. ${ }^{6}$ In them, learners report their own reflections on the second language learning process. These are reviewed periodically by the teacher and are very useful in measuring students' performance in the L2 and to what extent they have assimilated learning strategies. Not only do they demonstrate their capability to evaluate their own production in the language, but also their awareness of the factors involved in the process as well as the repertoire of possible tasks that could contribute to meeting the stated objectives.

In sum, in order to properly incorporate a strategy training procedure in the syllabus, an evaluation process is necessary and can suggest improvements. On the other hand, there may be some apparent difficulty in the implementation of the strategic component. One of the main objections is the time needed and "wasted" on complementary activities -those not specifically designed to meet a linguistic objective. Students are urged to turn their attention to their own mental processes in language learning rather than concentrating on certain grammatical aspects, commonly viewed as essential.

Yet it can be argued that while it is true that the entire syllabus cannot be completed as currently designed, the student will benefit from an informed strategy training. This will allow him/her to not only acquire certain linguistic knowledge on which s/he will be tested but, above all, $s$ /he will discover the means of approaching language learning and identify the tactics or operations that best work to achieve this end: "Self-assessment provides one of the most effective means of developing both critical self-awareness of what is to be a learner, and skills in learning how to learn" (Nunan The Learner-Centered Curriculum 116).

Lastly, strategy training cannot ignore the fact that each student is an individual with his/her own learning style and preferences (see chapter 4 of my Dissertation: Learning Style and Learning Strategies), and therefore s/he can benefit from knowing or applying other learning modes and perform a certain task. But a specific strategy can never be imposed as well stated by Ellis h Sinclair:

The term 'training' may seem to imply that learners are indeed taught specific behaviours rather than being encouraged to discover what works best for them as individuals. [...] we do not intend it (the term strategy training) to be understood as in any sense referring to a prescriptive approach (4).

In short, it is not a question of carrying out a preestablished set syllabus. The teacher may be tempted to do so when what really matters is "to encourage them to discover what works best for them as individuals", and mostly as learners.

We must not forget that students bring with them a 'hidden agenda' and what they learn is to a certain extent determined by it. This means that despite strategy training, we cannot take for granted that they will learn or even try to learn how to use strategies. Nunan (Understanding Language Classroom) once again addresses this issue. In his opinion, teachers should make an effort to reconcile the students' agenda to the official syllabus as much as possible. How? Negotiating the course contents and methodology with the class, inviting students to propose their own communicative objectives in the L2, training them in self- and course evaluation, and eventually introducing strategic components in the curriculum (learning-how-to-learn components). In conclusion, give the learner more 
independence, more freedom of choice and hence more responsibility in his/her language learning. This approach clearly coincides with the philosophy behind the new academic curricula in their attempt to make learners conscious of and committed to their own studies, and more precisely to their learning.

\section{Conclusion}

In this article, I have presented certain materials that enhance the use of language learning strategies in the context of conventional classroom instruction. The incorporation of strategy training into the teaching of English for mining engineering studies has been made possible by an intentional awareness raising approach on the part of the lecturer throughout the course. The proposed strategies do not involve additional language learning; instead, they are put forward to the learners in an explicit manner so that they realise how efficient these techniques are in practice. In fact, they are taught to assist students in the comprehension of oral and written discourse.

While students are accomplishing the tasks contained in the present unit, the teacher should make tham aware of the strategies that converge in the learning process, either through deliberate emphasis on their use, or by letting learners report their own repertoire of tactics employed in the completion of those activities. Such training does not constitute a separate, formal component of the instruction but it is integrated into the language learning experience.

The aim of this type of strategy training is to expose students to a number of strategies which may help them examine their approach to language learning, improve their language skills as well as monitor and assess their performance in the L2. In other words, make them autonomous in language learning by becoming more conscious of their own mental processes.

\section{Notes}

1. When considering "strategic competence", we are not referring to the strict sense of the term as defined by Canale and Swaim, taken as an integral part of communicative competence and relating primarily to communication strategies, but to the ability of the learner to monitor and assess his/her own learning in the L2 using all sorts of strategies. See also Anita Wenden's article on metacognition for this view.

2. The classroom is considered as a formal setting because language use is more concerned with information about the syntax, morphology and phonology of the L2, that is, the language itself as a structured, rule-bound system, whereas a natural setting is concerned with the use of language in communicative situations outside the classroom (going to movies, reading books, talking to native speakers...).

3. This listening passage is taken from the book Earth Sciences unit 4. The tapescript is in the teacher's manual with its corresponding cassette (see Appendix: E. Understanding a lecture).

4. The first part of the text is taken from a printed text of the book Earth Sciences and the second part is from the booklet Geology-Rocks and Minerals (see Appendix). 
5. We acknowledge with gratitude the permission of the publishing houses: Miliken Publishing Company. S.T.E.P. (Geology-Rocks and Minerals) and Prentice Hall-previously Cassell Publishers-(Earth Sciences) for allowing the reproduction of materials used in this paper.

6. Special attention should be paid to Prof. Manuel Jiménez's experience with diaries (presented in the paper entitled "The Role of Student Diaries in FL Learning" in IV Simposio sobre Estrategias de Aprendizaje y Uso del Lenguaje. Sevilla 1994) as well as to Prof. Ana Halbach's as stated in her paper "What Student Diaries can tell us about Strategy Use" (1997), in press.

\section{Works Cited}

Byalystok, E. "The Compatibility of Teaching and Learning Strategies." Applied Linguistics 6.3 (1985): 255-62.

Canale, M. and M. Swaim. "Theoretical Bases of Communicative Approaches to Second Language

Teaching and Testing." Applied Linguistics 1.1 (1980): 1-47.

Ellis, G. \& Sinclair, B. Learning to Learn English. Cambridge: Cambridge University Press, 1989.

Galloway, V. and A. Labarca. "From Student to Learner: Style, Process, and Strategy." New

Perspectives and New Directions in Foreign Language Education. Ed. Diane W. Birckbichler.

Lincolnwood, IL: NTC Publishing Group, 1990. 111-58.

Kindelán, P. Strategies used by Mining Engineering Students in an EAP Context. M.A. Dissertation

in Teaching English as a Foreign Language. Reading (England): U of Reading P, 1992.

Nunan, D. The Learner-Centered Curriculum. Cambridge: Cambridge University Press, 1988. Understanding Language Classrooms: A guide for teacher-initiated action. New York: Prentice Hall, 1989.

Ortleb, Edward. P. and R. Cadice. Geology-Rocks and Minerals. Distributed by Spain Training Education Program S.L. (educational audiovisual products). St. Louis, Missouri: Miliken, 1986.

Oxford, Rebecca L. Language Learning Strategies. What every teacher should know. Boston, MA:

Heinle, 1990.

"Use of Language Learning Strategies: a Synthesis of Studies with Implications for

Strategy Training." System 17 (1989): 1-13.

Oxford, Rebecca L. and Andrew D. Cohen. "Language Learning Strategies: Crucial Issues of Concept and Classification." Applied Language Learning 3.1\&2 (1992): 1-35.

Oxford, Rebecca L. and D. Crookall. "Research on Language Learning Strategies: Methods, Findings, and Instructional Issues." The Modern Language Journal 73.4 (1989): 404-9.

Oxford, Rebecca L., et al. "Strategy Training for Language Learners: Six Situational Case Studies and a Training Model." Foreign Language Annals 22.3 (1990): 197-216.

Weinstein, Claire E. and Vicki L. Underwood. "Learning Strategies: the How of Learning." Eds.

J.W. Segal, S.F. Chipman and R. Glaser Thinking and Learning Skills: Relating Instruction to Basic Research. Hillsdale, N.J.: Lawrence Erlbaum, 1985. 241-58.

Wenden, A. "Metacognition: An Expanded View on the Cognitive Abilities of L2 Learners." Language Learning 37.1 (1987): 573-97.

. Learner Strategies for Learner Autonomy. New York \& London: Prentice Hall, 1991.

Willing, K. "Learning Strategies as Information Management: Some Definitions for a Theory of Learning Strategies." Prospect 3.2 (1988): 139-55.

Yates, Christopher St. J. Earth Sciences. English for Academic Purposes. Ed. Vaughan James.

London: Cassell, 1988. 
Appendix

\section{ROCKS}

1 There is hardly any limit to the variety of rocks on the earth's surface. We find coarse-grained rocks and fine-grained rocks, light rocks and heavy rocks, soft rocks and hard rocks, rocks of all sizes, shapes, and colors. But close study reveals that there is order in this diversity, and a straightforward scheme for classifying rocks has been developed which simplifies the problem of understanding their origins and properties.

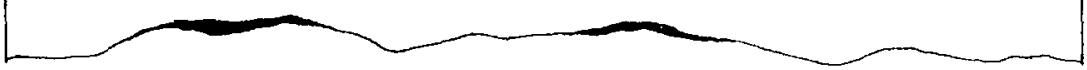

\section{Rock Classification}

2 At first glance, it is not obvious how rocks can be separated into definite categories. We might decide that a light-colored, coarse-grained rock like granite should belong in a different class from a dark, fine-grained volcanic rock like basalt, but we can find a whole series of rocks with properties transitional between the two, and so we cannot say just where one class ends and the other begins. The basic problem is to make distinctions that are not always clear-cut in nature.
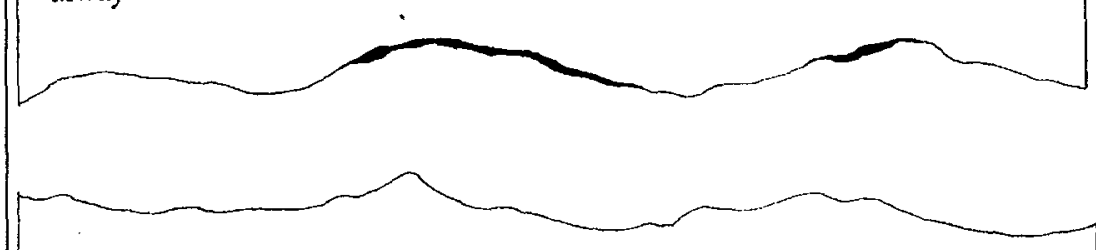

3 Since rocks are composed of minerals, we might guess first that they could be classified on the basis of the kinds and amounts of minerals they contain. But we find that rocks of widely different structures and origins have nearly the same mineral composition, and so we would be grouping together rocks of obviously different types. A classification based on chemical composition encounters the same difficulty, since it places in the same pigeonhole rocks that have little else in common; it has the further disadvantage that chemical compositions are not evident in the field but require laboratory analysis. We might disregard composition and classify rocks according to their origin. This would be an excellent method if it could be applied to all rocks, but the sad fact is that we simply do not know how some rocks were formed and the origin of many others can be determined only after lengthy study.

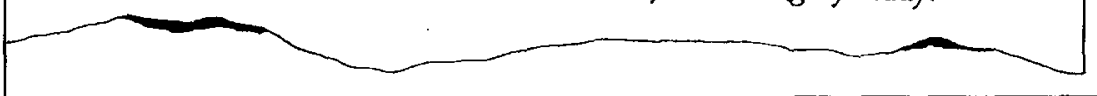




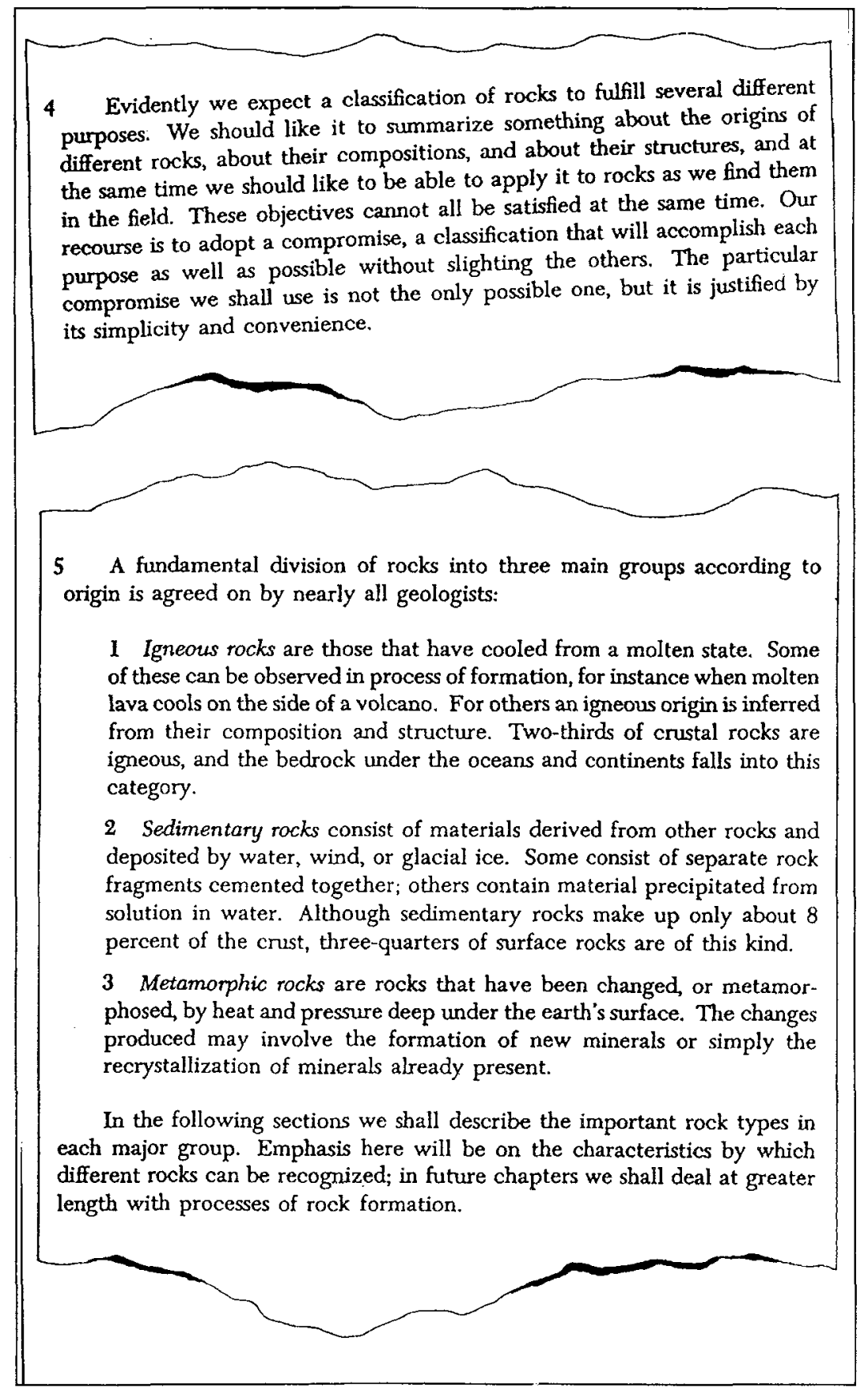




\section{FORMATION OF IGNEOUS ROCKS}

CONCEPT: Igneous rocks are formed from hot, molten material called magma.

BACKGROUND INFORMATION: Igneous rocks are formed from molten material deep below the earth's crust. This molten material is called magma. Magma may force its way up toward the surface of the earth through cracks in the rock strata. Lava, liquid magma that reaches the earth's surface, flows from volcanoes. cools rapidly, and forms rocks with small, fine-grained crystals or glassy appearances. Some examples of glassy rock with small crystals are basalt, pumice, and obsidian. Magma that is blocked from reaching the earth's surface by rock layers above it cools slowly below the land surface. Rocks formed under these conditions have large crystals and are coarse-grained in appearance. Some examples of this kind of rock are granites, the most common of igneous rocks, gabbro, quartz, and diabase.

\section{FORMATION OF SEDIMENTARY ROCKS}

CONCEPT: Nearly all sedimentary rocks. formed in layers or beds, are formed from layers of sediments that have been compressed under water for long periods of time.

BACKGROUND INFORMATION: When sediment.laden streams empty into larger bodies of water, the loss in velocity causes the larger and heavier particles to be deposited first. Smaller and lighter particles are carried away and settle farther from the moutin of the stream. The weight of the water plus the weight of the top layers press the sediment of the bottom layers tightly together. Chemicals lound in the water are deposited between the particles of sediment, fill the tiny spaces, and cement and form the sediment into rock layers. Common examples of sedimentary rock include conglomerates (formed by a compressed mixture of gravel usually deposited where rivers empty into larger bodies of water), sandstone (formed by compressed sand grains), and shaie (formed by compressed layers of clay, mud, and/or silt). Some kinds of sedimentary rocks are formed by sediments which include the remains of tiny plants and animals and dissolved chemicals, such as salt and calcium carbonates found in ocean water. Some examples are limestone, a very useful sedimentary rock, and gypsum. Both are formed from the remains of corals. plants, shells, and dissolved chemicals. 


\section{FORMATION OF METAMORPHIC ROCKS}

CONCEPTS: 1. Metamorphic rocks are formed from igneous, sedimentary, and other metamorphic rocks. 2 . These rocks are changed by heat, pressure, and chemical action.

BACKGROUND INFORMATION: Within the earth's crust, rocks are subjected to pressure and heat. The weight of overlying rock strata may produce great pres: sures on the rocks below them. It has been estimated that rocks lying several miles under the earth's surface may have pressures of four to twelve tons per square centimeter exerted upon them. This great pressure causes a physical readjustment or alignment of the mineral particles: Pressure on rocks may also be caused by the folditig of strata, as in the mountain-building process. As one goes deeper and deeper into the earth's crust, there is a corresponding increase in temperature. Temperatures around magma (liquid rock) intrusions are very high and may cause changes within the surrounding rocks. Often very hot gases and liquids asso. ciated with magma also cause a change in adjacent rocks. New elements may be added or elements may be removed. These changes can cause an alteration in the chemical composition of the rock. Metamorphic rocks are characterized by change in their texture due to recrystallization and/or their change in chemical composition.

Metamorphism can occur among igneous, sedimentary. and other metamorphic rocks. Often the original charac. teristics are profoundly changed. Metamorphic rocks may be more crystalline, more massive (dense), or have minerals arranged in parallel layers.

Marble Limestone changes into marble. Various im. purities in the limestone give marble its characteristic color. Marble, because of its compactness, is an excellent building stone and is used for statues.

Quartzite This rock comes from sandstone. Sandstone is composed of sand particles cemented together by various other materials. When crushed, sandstone breaks'arouñd the individual particles. Quartzite, how. ever, has particles cemented by a silica material and when crushed, the rock breaks through the particles. Slate Sediments such as silt form the sedimentary rock, shaie. When shale is subjected to metamorphism, it changes to slate. Slate is impervious to water, resistant to weathering, and easily splits into thin sections. These qualities have been utilized in its serviceability as a roofing material. Volcanic ash may metamorphose into slate.

Gneiss The various igneous granites may become changed into the rock called gneiss. It usually has a coarsely banded appearance consisting of successive dark and light bands. The dark bands may be the min. erals biotite or hornblende and the light bands, the minerals quartz or feldspar.

Anthracite Coal Bituminous caal becomes hard coal, anthracite. This rock is harder and has a greater carbon content than soft coal. Anthracite coal is found in are of mountain-building activity. Further metamorpho may change it into graphite. 


\section{E. Understanding a lecture}

\section{IAPESCRIPI}

Listen to this lecture on six common minerals. The minerals the leclurer will be talking about are quartz, feldspar, mica, ferromagnesian minerals, clay minerals and calcite. The lecture is divided into six sections, one on each mineral. Using the information the lecturer gives you, complete as much of the table in your book as you can. look at the table first, so you can see what iniormation vou are looking for. Stop your cassette and do that now.

Now that you have looked at the lable, here is the first sectron on quartz. Listen to each section twice.

The first of the six common minerals I am going to talk about is quartz. The formula for quartz is S-i-O-2. That is, of course. capital 5, small $i$, capital $O$ with the subscript 2. When they dre well-formed, quartz crystais come as six-sided prisms and pyramids. Prism you spell P-R-I-S-M. Quartz crystals not only have different shapes, but also different colours. Some are colourless, in other words clear. But they can also appear milky. often grey, pink or violet. This is because of impurities. Quartz occurs in many kinds of rocks, often in aggregates of well-formed crystals on the sides of cavities. As for hardness, they are hard enough to scraich glass and feldspar. What do we use quartz for? There are two main uses. Clear quartz is used in both jewellery and optical instruments. The coloured varieties are, like clear quart?. used in jewellery.

WD

KEY
The next common mineral we can look at today is feldspar Feldspar is the name of a group of silicate minerals. We divide feldspar into two classes, orthoclase and plagioclase. The two classes are very much the same. In shape, the crystals are reclangular. They have blunt-pointed ends. Like quartz, teldspar crystals can be clear. They can also be white, or light shades of grey and pink. Feldspar is the commonest single constituent of rocks, making up about 60 percent of the total weight of the earth's crust As for hardness, feldspar is a little harder than glass. It is not as hard as quanz. Pure teldspar is used to make porcelain, a kind of china. for example cups and plates.

\section{WD}

Let us lurn to mica. I don't have much to say here, as this is a mineral you have met before. But I will just say that there are two varieties of mica, black and while. Mica is a very soft mineral, softer than quartz. While mica, if it has no impurties, is used as an insulator in electrical equipment.

\section{Wh}

The next kind ot mineral I wan to look briefly at are the ferromagnesian minerals. The name ferromagnesian minerals really refers to a number of ninerals with different properties. What they have in common is that they are all silicates of iron and magnesium. Ther are nearly all a dark green through to black in colour. Most of these minerals contain other metallic elements in additon to iron and magnesium, for example calcium. But as we cannot set down ant general properties tor this group, except colour and composition we'll leave the group there ior the moment

\section{H.}

Let's turn now to clay minerals. Clay minerals are aggregates of microscopic crvstals, which when they are pure are white or light coloured. However, they are otten discoloured by iron compounds. Clay ninerals ast very solt, so soft in fact that when you rub them between your lingers they form a smooth powder. One clay mineral. kan!n, is used to make paper, paint and certain plastics.

\section{(H)}

Finalh, we come lo calcile, for which the formula is capital $C_{\text {, }}$ small a, capital $C$, capital $O$, subscript 3 . In shape, calcile crystais are hexagonal, that is to say six-sided. As for their colour, calcite crystals can be clear, that is colourless. They can also be any light shade. As for hardness, calcite is hard enough to scratch mica, but it can be itself scraiched by glass. As for its uses, calcile serves as a source oi lime when we make glass or, for example, cement.

\begin{tabular}{lllll}
\hline Mineral & Formula & Colour & Hardness & Uses \\
\hline Quartz & $\mathrm{SiO}_{2}$ & Various & Can scratch glass and feldspat & lewellery, optical instruments \\
\hline Feldspar & & Various & Little harder than glass & Porcelain \\
\hline Mica & Black \& white & Very soft & $\begin{array}{l}\text { Insulator in electrical } \\
\text { equipment }\end{array}$ \\
\hline Ferromagnesian minerals & Dark green to black & & \\
\hline Clay minerals & $\begin{array}{l}\text { White or light-coloured } \\
\text { when not discoloured }\end{array}$ & Very soft & $\begin{array}{l}\text { Paper, paint, certain plastics } \\
\text { (kaolin) }\end{array}$ \\
\hline Calcite & CaCO, & Light colours & $\begin{array}{l}\text { Can scratch mica, be scratched Glass, cement } \\
\text { by glass }\end{array}$ & \\
\hline
\end{tabular}

